\title{
Salmonella Infection in Nursery Piglets and Its Role in the Spread of Salmonellosis to Further Production Periods
}

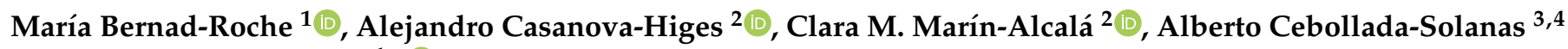 \\ and Raúl C. Mainar-Jaime ${ }^{1, *(\mathbb{D}}$ \\ 1 Departamento de Patología Animal, Facultad de Veterinaria, Instituto Agroalimentario de Aragón-IA2, \\ Universidad de Zaragoza-CITA, 50013 Zaragoza, Spain; mbernadroche@gmail.com \\ 2 Unidad de Producción y Sanidad Animal, Centro de Investigación y Tecnología Agroalimentaria de Aragón, \\ Instituto Agroalimentario de Aragón-IA2, Universidad de Zaragoza-CITA, 50059 Zaragoza, Spain; \\ casanova.alejandro89@gmail.com (A.C.-H.); cmarin@unizar.es (C.M.M.-A.) \\ 3 Grupo de Genética de Micobacterias, Departamento de Microbiología, Medicina Preventiva y Salud Pública, \\ Universidad de Zaragoza, 50009 Zaragoza, Spain; alberto@unizar.es \\ 4 Unidad de Biocomputación, Instituto Aragonés de Ciencias de la Salud (IACS/IIS Aragón), Centro de \\ Investigación Biomédica de Aragón (CIBA), 50009 Zaragoza, Spain \\ * Correspondence: rcmainar@unizar.es; Tel.: +34-976762088
}

check for updates

Citation: Bernad-Roche, M.; Casanova-Higes, A.; Marín-Alcalá, C.M; Cebollada-Solanas, A.;

Mainar-Jaime, R.C. Salmonella Infection in Nursery Piglets and Its Role in the Spread of Salmonellosis to Further Production Periods.

Pathogens 2021, 10, 123. https://

doi.org/10.3390/pathogens 10020123

Academic Editors: Joana Mourão and Patrícia Antunes

Received: 10 December 2020

Accepted: 21 January 2021

Published: 25 January 2021

Publisher's Note: MDPI stays neutral with regard to jurisdictional claims in published maps and institutional affiliations.

Copyright: (c) 2021 by the authors. Licensee MDPI, Basel, Switzerland. This article is an open access article distributed under the terms and conditions of the Creative Commons Attribution (CC BY) license (https:// creativecommons.org/licenses/by/ $4.0 /)$.

\begin{abstract}
Few studies have focused on assessing Salmonella infection in the nursery and its role in further pig production periods. Mesenteric lymph nodes, intestinal content, and meat juice from 389 6-week-old male piglets intended for human consumption from five breeding farms and 191 pooled floor fecal samples from gilt development units (GDU) from the same farms were analyzed to estimate and characterize (by pulsed-field gel electrophoresis and antimicrobial resistance analyses) Salmonella infection. The prevalence of infection and shedding among piglets was $36.5 \%$ and $37.3 \%$, respectively, shedding being significantly associated with infection (Odds Ratio $=12.7$; CI 7.3-22.0). Salmonella Rissen; S. 4,[5],12:i:-; and S. Derby were the most common serotypes. A low level of Salmonella-specific maternal antibodies at the beginning of the nursery period suggested it was a period of high risk of infection. Resistance to 3rd- and 4th-generation cephalosporins was detected in piglet isolates although the piglets never received antibiotics, indicating they could be vectors of antimicrobial resistance. The same Salmonella clones were detected in piglet and GDU isolates, suggesting that infected piglets play a significant role in the infection of gilts and consequently of finishing pigs in the case of production farms. The control of Salmonella infection in nursery piglets may decrease the risk of abattoir and carcass contamination.
\end{abstract}

Keywords: nursery piglets; prevalence; Salmonella; swine; shedding; PFGE; zoonoses

\section{Introduction}

Salmonella infection is quite common in pigs in the European Union [1]. It usually courses asymptomatically, but infected pigs may shed the bacterium through their feces, making them a major risk factor for carcass contamination at slaughter [2]. Since the presence of Salmonella during the growing-finishing phase is directly related to carcass contamination at abattoirs, main mitigation measures have been usually directed toward this production period [3-6]. However, few studies have focused on the periods previous to this one, such as the nursery, although active Salmonella infections have been identified in pig nurseries [7].

The so-called nursery is a period that comprises the time from weaning at 3-4 weeks of age to approximately 10 weeks of age (just before entering the growing unit). This is a critical production phase in which piglets are very susceptible to a variety of enteric infections. A common consequence of weaning is the modification of the piglets' intestinal microbiota, characterized by a significant reduction in the number of lactobacilli [8], mostly 
due to sudden changes in their diet, which goes from mostly liquid (sow milk) during lactation to a solid-based diet (prestarter feed) at the beginning of the nursery, and environment [9]. These changes, along with the decay of maternal antibodies [10], the only immune protection at this age, and the usual animal stress linked to the piglet's separation from its dam and its commingling with new piglets, make weaned piglets highly prone to Gram-negative bacterial infections, such as Escherichia coli and Salmonella spp. [11].

While E. coli infection has been widely studied and is confirmed as a prevalent enteric pathogen at this age [12], the prevalence of Salmonella infection has been barely studied. However, it is accepted that weaning- or post-weaning-age pigs would be among the most clinically affected had they become infected by Salmonella [2]. Both are closely related bacteria that are susceptible to the same class of antibiotics, so the treatments against colibacillosis may be hindering Salmonella infections at this age. Indeed, until recently, the use of antimicrobials as prophylactics, mostly aminoglycosides and polymyxins (colistin), was a common practice in intensive pig husbandry systems, particularly during the nursery period $[13,14]$. In Spain, colistin was commonly administered, for as long as 15 days, as an in-feed antimicrobial for years, due to its high efficacy against Gram-negative bacteria [15].

In a recent study, we observed that Salmonella prevalence in suckling piglets from seropositive breeding farms was high, confirming that apparently healthy 4-week-old (wo) piglets may act as carriers of infection at least until weaning [16]. Considering the likely high proportion of Salmonella-infected piglets at weaning, it is likely that the nursery will be heavily infected by this pathogen as well. Therefore, it seems logical to think that during the past few years, Salmonella infection has been overlooked during the nursery period due to preventive antimicrobial treatments.

The alarming increase in antimicrobial resistance triggered the European health authorities to set up new European Union regulations on the use of colistin in veterinary medicine, and since 2015, colistin has been banned for use as a prophylactic [14]. These new regulations may favor an increasing incidence of salmonellosis in the nursery. However, to the best of the authors' knowledge, no field studies on Salmonella prevalence during the nursery period have been carried out so far. Thus, in this study, we first assess the prevalence of Salmonella infection at the beginning of the nursery period, i.e., two weeks after weaning, in a piglet population that came from a group of Salmonella-seropositive breeding farms. Further, we characterize by pulsed-field gel electrophoresis (PFGE) and antimicrobial susceptibility analyses the Salmonella isolates obtained and compare them to those isolated from gilt development units (GDU) from the same herds. Results from this study may help to shed some light on the role that Salmonella infection in nursery piglets may play in subsequent production periods, such as growing/finishing, and therefore in abattoir and carcass contamination.

\section{Results}

\subsection{Salmonella Isolation, Serotyping, and Serology in Piglets}

A total of 389 weaned piglets were sampled from Salmonella-seropositive breeding farms (an average of 78 piglets per farm). Piglets were sampled in all seasons (35.7\% in winter, $23.4 \%$ in spring, $22.4 \%$ in summer, and $18.5 \%$ in autumn). Table 1 shows the distribution of the sampling by farm and the corresponding prevalence of infection (Salmonellapositive in mesenteric lymph nodes) and shedding (Salmonella-positive in intestinal content). The prevalence of infection varied significantly between farms, ranging from $17.5 \%$ (farm E) to $59.2 \%$ (farm D), with an average of $36.5 \%$ (95\% CI 31.9-41.4). The prevalence of shedding piglets also varied significantly between farms, with a similar mean value $(37.3 \%$; $95 \%$ CI 32.6-42.2). 
Table 1. Results for Salmonella isolation * from intestinal content (IC) and mesenteric lymph nodes (MLN) in 6-week-old nursery piglets.

\begin{tabular}{ccccc}
\hline Farm & No. of Piglets & $\begin{array}{c}\text { No. of } \\
\text { MLN-Positive (\%) }\end{array}$ & $\begin{array}{c}\text { No. of } \\
\text { IC-Positive (\%) }\end{array}$ & $\begin{array}{c}\text { No. of IC- and } \\
\text { MLN-Positive (\%) }\end{array}$ \\
\hline A & 96 & $39(40.6)$ & $47(48.9)$ & $31(56.4)$ \\
\hline B & 75 & $34(45.3)$ & $26(34.7)$ & $20(50.0)$ \\
\hline C & 89 & $26(29.2)$ & $34(38.2)$ & $22(57.9)$ \\
\hline D & 49 & $29(59.2)$ & $22(44.9)$ & $20(64.5)$ \\
\hline E & 80 & $14(17.5)$ & $16(20.0)$ & $11(57.9)$ \\
\hline Total & 389 & $142(36.5)$ & $145(37.3)$ & $104(56.8)$ \\
\hline
\end{tabular}

*International Organization for Standardization (ISO) 6579:2002/A1:2007. ** Percentage estimated from positive (either IC or MLN) piglets.

A median of $14.4 \mathrm{~g}$ (95\% CI 13.96-15.00) of MLN was collected. No significant difference was observed between the weight of MLN-positive and MLN-negative samples (median of 15.0 and $14.1 \mathrm{~g}$, respectively; $p=0.31$ ).

All Salmonella isolates (145 from IC samples and 142 from MLN samples) were serotyped. The distribution of Salmonella serotypes by farm and type of sample is shown in Table 2. Salmonella Rissen was the most frequent serotype (42.8\%) recovered from IC samples, followed by the monophasic variant of $S$. Typhimurium (S. 4,[5],12:i:-) (40.0\%), and $S$. Derby (4.8\%). A similar distribution of serotypes was observed in MLN-positive samples, with S. 4,[5],12:i:- (40.8\%) and S. Rissen (31.0\%) being the most prevalent, followed by $S$. Brandenburg (10.6\%). Salmonella 4,[5],12:i:- was the only serotype present in all farms.

Table 2. Distribution of Salmonella serotypes in 6-week-old nursery piglets and in gilt development units (GDU) among the 5 farms.

\begin{tabular}{|c|c|c|c|c|c|c|c|}
\hline \multirow{3}{*}{ Farm } & \multicolumn{4}{|c|}{ Piglet Isolates } & \multirow{3}{*}{$\begin{array}{l}\text { No. of Piglets with } \\
\text { the Same Serotype } \\
\text { in MLN-IC }\end{array}$} & \multirow{2}{*}{\multicolumn{2}{|c|}{ GDU Isolates }} \\
\hline & \multicolumn{2}{|c|}{ IC } & \multicolumn{2}{|c|}{ MLN } & & & \\
\hline & Serotype & No. (\%) & Serotype & No. (\%) & & Serotype & No. (\%) \\
\hline \multirow{5}{*}{ A } & Rissen & $25(53.2)$ & Rissen & $19(48.7)$ & 17 & Rissen & $11(78.6)$ \\
\hline & 4,[5],12:i:- & $15(31.9)$ & 4,[5],12:i:- & $17(43.6)$ & 9 & Anatum & $2(14.3)$ \\
\hline & Derby & $4(8.5)$ & Brandenburg & $1(2.6)$ & & 4,[5],12:i:- & $1(7.1)$ \\
\hline & Kapemba & $2(4.3)$ & Goldcoast & $1(2.6)$ & & & \\
\hline & Typhimurium & $1(2.1)$ & London & $1(2.6)$ & & & \\
\hline \multirow{5}{*}{ B } & Rissen & $12(46.2)$ & Rissen & $8(23.5)$ & 5 & Rissen & $4(66.6)$ \\
\hline & 4,[5],12:i:- & $5(19.2)$ & 4,[5],12:i:- & $8(23.5)$ & 3 & Brandenburg & $1(16.7)$ \\
\hline & Goldcoast & $5(19.2)$ & Goldcoast & $3(8.8)$ & 3 & 4,[5],12:i:- & 1 (16.7) \\
\hline & Brandenburg & $3(11.5)$ & Brandenburg & $13(38.2)$ & 3 & & \\
\hline & Derby & $1(3.8)$ & Derby & $2(5.9)$ & 1 & & \\
\hline \multirow{5}{*}{$\mathrm{C}$} & Rissen & $23(67.6)$ & Rissen & $13(50)$ & 12 & Rissen & $10(83.3)$ \\
\hline & 4,[5],12:i:- & $7(20.6)$ & 4,[5],12:i:- & $6(23.1)$ & 2 & Derby & $2(16.7)$ \\
\hline & Derby & $2(5.9)$ & Derby & $5(19.2)$ & 1 & & \\
\hline & Anatum & $1(2.9)$ & Anatum & $1(3.8)$ & 1 & & \\
\hline & Kedougou & $1(2.9)$ & Typhimurium & $1(3.8)$ & & & \\
\hline \multirow{4}{*}{$\mathrm{D}$} & 4,[5],12:i:- & $19(86.3)$ & 4,[5],12:i:- & $18(62.1)$ & 15 & Derby & $7(70.0)$ \\
\hline & Goldcoast & $1(4.5)$ & Goldcoast & $9(31.0)$ & 1 & Rissen & $3(30.0)$ \\
\hline & Brandenburg & $1(4.5)$ & Brandenburg & $1(3.4)$ & 1 & & \\
\hline & Ohio & $1(4.5)$ & Ohio & $1(3.4)$ & 1 & & \\
\hline \multirow{4}{*}{$\mathrm{E}$} & 4,[5],12:i:- & $12(75.0)$ & 4,[5],12:i:- & $9(64.3)$ & 8 & Rissen & $8(88.9)$ \\
\hline & Rissen & $2(12.5)$ & Rissen & $4(28.6)$ & 2 & 4,[5],12:i:- & $1(11.1)$ \\
\hline & Anatum & $1(6.3)$ & Anatum & $1(7.1)$ & 1 & & \\
\hline & Agona & $1(6.3)$ & & & & & \\
\hline Total & & 145 & & 142 & 86 & & 51 \\
\hline
\end{tabular}


Salmonella was not detected in 206 (52.9\%) of the sampled piglets, while positive results in both MLN and IC samples were obtained for $104(26.7 \%)$ of them. The same serotype was detected in $86(82.7 \%)$ of the animals with positive MLN and IC cultures (Table 2). A significant association between the isolation of Salmonella in MLN and IC samples was observed: an MLN-positive piglet had around 12 times higher odds of shedding Salmonella than an MLN-negative piglet (OR $=12.7 ; \mathrm{CI} 7.3-22.0 ; p<0.001$ ) once the season and farm effects were accounted for (Table 3 ).

Table 3. Association between Salmonella shedding and Salmonella infection in 6-week-old nursery piglets by mixed logistic regression analysis *.

\begin{tabular}{ccccc}
\hline & No. of Piglets & No. (\%) of IC-Positive Piglets & \multicolumn{2}{c}{ Logistic Regression Parameters } \\
95\% CI (OR) & OR & - \\
\hline MLN & & & 1 & - \\
Negative & 247 & $41(16.6)$ & 12.71 & $7.33-22.05$ \\
Positive & 142 & $104(73.2)$ & & - \\
Season & & & 1 & $0.55-2.51$ \\
Winter ${ }^{1}$ & 139 & $33(23.7)$ & 1.17 & $1.31-5.55$ \\
Spring & 91 & $26(28.6)$ & 2.69 & 0.001 \\
Summer & 87 & $56(64.4)$ & 2.53 & $1.22-5.26$ \\
Autumn & 72 & $30(41.7)$ & 0.013 \\
\hline
\end{tabular}

${ }^{*}$ Farm used as grouping factor. ${ }^{1}$ Reference category. IC: intestinal content; MLN: mesenteric lymph nodes; OR: odds ratio.

Regarding serological results, the median optical density percentage (OD \%) value for the 389 sampled animals was 4.7 (95\% CI 3.0-6.0). No significant differences were observed between MLN-negative and MLN-positive piglets (median of 4.8 and 4.7, respectively; $p=0.5)$. No significant differences were observed either in OD \% values between ICnegative and IC-positive piglets (median of 5.2 and 4.0 , respectively; $p=0.1$ ).

\subsection{Salmonella Isolation, Serotyping, and Serology in Gilt Development Units (GDU)}

A total of 191 pooled floor fecal samples from 5 GDU were collected. Salmonella was isolated from 51 of them $(26.7 \%$; $95 \%$ CI 20.9-33.4), but the proportion of positive samples in the growing units varied among farms, ranging from $17.5 \%$ to $43.8 \%$ (Table 4 ). The most frequent serotype was $S$. Rissen $(70.6 \%)$, which was present in all farms $(A, B, C, D$, and E), followed by S. Derby (17.6\%; farms C and D) and S. 4,[5],12:i:- (5.9\%; farms A, B, and E). In all the farms, except farm D, the serotypes found in the GDU were also detected in the nursery piglets (Table 2). Thus, the same serotypes, i.e., S. 4,[5],12:i:- and $S$. Rissen in farm A; S. 4,[5],12:i:-, S. Rissen, and S. Brandenburg in farm B; S. Rissen and S. Derby in farm C; and $S .4,[5], 12: i$ :- and $S$. Rissen in farm E, were observed in piglets and floor samples from gilt units (Table 2).

Four hundred and twenty-one gilt serum samples were available from four farms (A, B, C, and E; Table 4). The mean seroprevalence was $24.2 \%$ (95\% CI 20.4-28.5). Among gilt units, seroprevalence varied slightly (from a minimum of $19.3 \%$ in farm E to a maximum of $31.9 \%$ in farm $\mathrm{A})$.

Table 4. Results for Salmonella isolation * in floor fecal samples from gilt development units and Salmonella seroprevalence ** in gilts from the 5 farms.

\begin{tabular}{ccccc}
\hline Farm & $\begin{array}{c}\text { No. of Floor Fecal } \\
\text { Samples }\end{array}$ & $\begin{array}{c}\text { No. of Positive Floor Fecal } \\
\text { Samples (\%) } *\end{array}$ & $\begin{array}{c}\text { No. of Serum } \\
\text { Samples }\end{array}$ & $\begin{array}{c}\text { No. of Seropositive } \\
\text { Samples (\%) } * *\end{array}$ \\
\hline A & 32 & $14(43.8)$ & 91 & $29(31.9)$ \\
B & 24 & $6(25.0)$ & 90 & $25(27.8)$ \\
C & 32 & $12(37.5)$ & 90 & $19(21.1)$ \\
D & 57 & $10(17.5)$ & NA & - \\
E & 46 & $9(19.6)$ & 150 & $29(19.3)$ \\
Total & 191 & $51(26.7)$ & 421 & $102(24.2)$ \\
\hline
\end{tabular}

* ISO 6579:2002/A1:2007. ** Considering a cutoff value of OD\% $\geq 40 \%$ (Herdcheck Swine Salmonella ELISA test, IDEXX Laboratories, USA); NA: not available. 


\subsection{Pulsed-Field Gel Electrophoresis (PFGE)}

PFGE analysis was performed when the same Salmonella serotype was detected in piglets and floor fecal samples from gilt units from the same farm. Thus, a total of 37 Salmonella isolates from IC-positive piglets ( 15 from farm A, 9 from farms B and C, and 4 from farm E) and 17 from the GDU ( 5 from farm A, 2 from farm B, 6 from farm C, and 4 from farm E) were submitted for PFGE analysis. Isolates of $S$. Brandenburg from the gilt unit of farm $B$ were not available.

PFGE analysis of these 54 Salmonella isolates showed 12 different XbaI patterns (based on a similarity cutoff of $\geq 90 \%$ ) (Figure 1). Observed PFGE clusters matched well with serotypes and antimicrobial resistance (AMR) profiles. When analyzed by serotype, six main clusters were observed for S. 4,[5],12:i:-, four for S. Rissen, and two for S. Derby.

\begin{tabular}{|c|c|c|c|c|c|c|c|c|c|}
\hline ? & ه & 8 & Cluster & Sample ID & Farm ID & Serotype & AMR profile & Source & Date \\
\hline & & & 1 & 46 & A & $4,[5], 12: \mathrm{i}--$ & ACST & piglet & 2012-06-19 \\
\hline & & & 1 & 61 & E & $4,[5], 12: \mathrm{i}--$ & ACST & gilt unit & $2015-06-22$ \\
\hline & & & 1 & 22 & A & $4,[5], 12: \mathrm{i}--$ & ACST & piglet & 2013-01-15 \\
\hline & & & 1 & 31 & A & $4,[5], 12: \mathrm{i}--$ & AST & piglet & $2013-05-28$ \\
\hline & & & 1 & 25 & A & 4,[5],12:i:- & AST & piglet & $2013-01-22$ \\
\hline & & & 1 & 7 & A & $4,[5], 12: \mathrm{i}--$ & AST & gilt unit & $2013-05-28$ \\
\hline & & & 1 & 27 & B & 4,[5],12:i:- & ACST & piglet & $2013-01-22$ \\
\hline & & & 1 & 2 & B & $4,[5], 12: \mathrm{i}--$ & CST & gilt unit & 2013-01-31 \\
\hline & & & 2 & 59 & E & 4,[5],12:i:- & AST & piglet & 2016-02-04 \\
\hline & & & -3 & 19 & A & 4,[5],12:i:- & ACST & piglet & $2012-12-11$ \\
\hline & & & 4 & 57 & C & 4,[5],12:i:- & ACST & piglet & $2012-09-18$ \\
\hline & & & -4 & 53 & A & $4,[5], 12: \mathrm{i}--$ & ACST & piglet & 2012-09-18 \\
\hline & & & 5 & 55 & B & $4,[5], 12: \mathrm{i}--$ & ACST & piglet & $2012-09-18$ \\
\hline & & & 5 & 16 & B & $4,[5], 12: \mathrm{i}--$ & ACST & piglet & $2012-09-25$ \\
\hline & & & -5 & 13 & A & $4,[5], 12: \mathrm{i}--$ & ACST & piglet & $2012-09-25$ \\
\hline & & & -6 & 35 & E & $4,[5], 12: \mathrm{i}--$ & ACS & piglet & $2015-10-29$ \\
\hline & & & -7 & 9 & E & Rissen & $\operatorname{cscf}$ & gilt unit & 2015-11-04 \\
\hline & & & -7 & 11 & c & Rissen & ACSSUT & gilt unit & 2016-05-30 \\
\hline & & & 7 & 10 & E & Rissen & ACSSUT & gilt unit & $2016-02-29$ \\
\hline & & & 7 & 60 & E & Rissen & ACSSuT & gilt unit & $2015-03-23$ \\
\hline & & & 7 & 36 & E & Rissen & ACSSUT & piglet & 2015-03-19 \\
\hline & & & 7 & 5 & A & Rissen & ACST & gilt unit & 2013-02-05 \\
\hline & & & 8 & 32 & A & Rissen & ACSSUT & piglet & $2013-05-28$ \\
\hline & & & 8 & 30 & B & Rissen & ACST & piglet & 2013-03-20 \\
\hline & & & 8 & 28 & A & Rissen & ACSTCf & piglet & $2013-03-20$ \\
\hline & & & 8 & 42 & A & Rissen & ACSSuT & gilt unit & $2012-09-25$ \\
\hline & & & 8 & 34 & B & Rissen & ACSSuT & piglet & $2013-05-28$ \\
\hline & & & -8 & 12 & A & Rissen & ACSSuT & piglet & $2012-09-25$ \\
\hline & & & -8 & 47 & A & Rissen & ACST & piglet & 2012-07-17 \\
\hline & & & 8 & 17 & C & Rissen & ACSSUTCf & piglet & $2012-09-25$ \\
\hline & & & 78 & 48 & c & Rissen & ACSSUTCFNa & piglet & $2012-07-17$ \\
\hline & & & -8 & 23 & B & Rissen & CSSuT & piglet & 2013-01-15 \\
\hline & & & -8 & 20 & B & Rissen & ACSSUT & piglet & $2012-12-11$ \\
\hline & & & -8 & 52 & A & Rissen & ACST & piglet & 2012-09-18 \\
\hline & & & -8 & 58 & E & Rissen & CST & piglet & $2015-10-29$ \\
\hline & & & 8 & 56 & c & Rissen & ACSSuT & piglet & 2012-09-18 \\
\hline & & & 8 & 38 & c & Rissen & ACSSuT & gilt unit & 2012-05-09 \\
\hline & & & 8 & 45 & A & Rissen & ACST & piglet & $2012-05-29$ \\
\hline & & & 8 & 39 & A & Rissen & CST & gilt unit & 2012-05-15 \\
\hline & & & 8 & 40 & B & Rissen & CST & gilt unit & 2012-05-31 \\
\hline & & & 9 & 51 & c & Rissen & ACSSUTCFNa & piglet & 2012-09-11 \\
\hline & & & 9 & 49 & A & Rissen & ACSSUTCFNa & piglet & 2012-09-11 \\
\hline & & & 9 & 50 & B & Rissen & ACSSUTCFNa & piglet & 2012-09-11 \\
\hline & & & -9 & 24 & c & Rissen & ACST & piglet & 2013-01-15 \\
\hline & & & 9 & 29 & B & Rissen & CST & piglet & 2013-03-20 \\
\hline & & & 9 & 8 & c & Rissen & ACSSUT & gilt unit & 2013-06-05 \\
\hline & & & 9 & 14 & A & Rissen & ACSSUT & piglet & $2012-09-25$ \\
\hline & & & 9 & 6 & A & Rissen & Acssu & gilt unit & $2013-05-28$ \\
\hline & & & 9 & 41 & c & Rissen & ACST & gilt unit & $2012-09-19$ \\
\hline & & & -10 & 1 & c & Rissen & ACSSuTCFNa & gilt unit & $2013-01-23$ \\
\hline & & & 11 & 43 & c & Derby & CS & piglet & 2012-04-17 \\
\hline & & & 11 & 37 & C & Derby & CS & gilt unit & 2012-05-09 \\
\hline & & & 11 & 44 & c & Derby & ACsSuT & piglet & $2012-04-17$ \\
\hline & & & 12 & 18 & C & Derby & ACSSUT & piglet & $2012-09-25$ \\
\hline
\end{tabular}

Figure 1. Dendrogram showing the main XbaI pulsed-field gel electrophoresis (PFGE) patterns ( $\geq 90 \%$ homology) for 54 Salmonella strains isolated from piglets' intestinal content and GDU from 4 farms (A, B, C, and E). A, aminopenicillins; C, phenicols; S, aminoglycosides; Su, sulfonamides; T, tetracyclines; $\mathrm{Na}$, quinolones; $\mathrm{Cf}$, 3rd- or 4th-generation cephalosporins. 
Salmonella isolates from the GDU were grouped into six different PFGE patterns, and within five of them isolates from piglets from the corresponding farm were included (patterns 1, 7, 8, 9, and 11; Figure 1). Overall, 75.7\% of the piglet isolates analyzed were included within these five clusters. At least one genetic relationship between Salmonella isolates from piglet fecal samples and floor fecal samples from the corresponding GDU was detected in all four farms.

In the case of isolates from piglets, genetically similar serotypes were detected on several occasions within the same farm and sometimes more than 150 days apart (i.e., S. 4,[5],12:i:and S. Rissen in farm A, S. Rissen in farm B, and S. Rissen and S. Derby in farm C).

When looking at pairs of homologous Salmonella isolates coming from piglets and GDU, isolates of five of these pairs were collected within a short ( $<1$ month) period of time, namely one $S$. Rissen pair from farm A, one $S .4,[5], 12$ :i:- from farm B, one $S$. Rissen and one $S$. Derby from farm $C$, and one $S$. Rissen from farm E. In another five pairs, the piglet isolates were collected far before ( $>150$ days before) the gilt samples (one $S$. Rissen from farm A, one S. 4,[5],12:i:- from farm B, one $S$. Rissen and one $S$. Derby from farm C, and one S. Rissen from farm E). In two more (one $S$. Rissen from farm B and one from farm C), the piglet isolates were collected far after gilt samples had been obtained (Figure 1).

\subsection{Antimicrobial Resistance}

All 54 isolates submitted to PFGE were also tested for AMR against 17 antimicrobial agents, as described below. All but two $S$. Derby displayed multidrug resistance (MDR), both isolated from farm $C$ (Table 5). A total of 11 multi-AMR profiles were detected, the most common being ACST ( $n=1731.5 \%$ ) and ACSSuT ( $n=15,27.8 \%)$, both of them mostly associated with $S$. Rissen and detected in all the farms (Figure 1). The most common phenotypic resistance was against florfenicol (92.6\%), tetracycline (90.7\%), ampicillin $(83.3 \%)$, and trimethoprim-sulfamethoxazole (42.6\%).

Table 5. Antimicrobial resistance (AMR) patterns found in the 54 Salmonella isolates from 6-week-old nursery piglets and gilt development units.

\begin{tabular}{cccc}
\hline AMR Family Pattern * & No. of Strains & Serotypes Involved (No. of Strains) & Farm \\
\hline ACS & 1 & $4,[5], 12: i:-$ & E \\
ACSSu & 1 & Rissen & A \\
ACSSuT & 15 & Rissen (13), Derby (2) & A, B, C, E \\
ACSSuTCf & 1 & Rissen & C \\
ACSSuTCfNa & 5 & Rissen & A, B, C \\
ACST & 17 & $4,[5], 12: i:-(10)$, Rissen $(7)$ & A, B, C, E \\
ACSTCf & 1 & Rissen & A \\
AST & 4 & $4,[5], 12: i:-$ & A, E \\
CS & 2 & Derby & C \\
CSCf & 1 & Rissen & E \\
CSSuT & 1 & Rissen & B \\
CST & 5 & Rissen (4), 4,[5],12:i:- (1) & A, B, E \\
\hline
\end{tabular}

* A, aminopenicillins; C, phenicols; S, aminoglycosides; Su, sulfonamides; T, tetracyclines; Na, quinolones; Cf 3rd- or 4th-generation cephalosporins.

Regarding resistance to antimicrobials of critical importance for humans, no AMR against carbapenems (imipenem) or polymyxins (colistin) was detected in any of the isolates analyzed. However, AMR against cephalosporins of 3rd (ceftiofur) and 4th (cefquinome) generations was detected in $13.0 \%(7 / 54)$ and $5.6 \%(3 / 54)$ of the isolates, respectively. All of them were $S$. Rissen.

\section{Discussion}

To properly assess the true prevalence of Salmonella infection in nursery units at a pig farm is quite challenging and expensive, as it requires the killing of a large number of young animals (between 4 and 10 weeks of age) that are usually intended for other purposes, 
i.e., either for slaughter at market age (5-6 months old) or as replacement animals. For this study, piglets came from five breeding farms where female weaned piglets were raised as restocking gilts for other pig production farms, while male piglets were fattened up to 7-9 kg live weight and then slaughtered for human consumption. These male piglets were weaned when they were 4 wo and fed for two more weeks, until slaughtering. This management allowed us to analyze MLN, IC, and meat juice samples in order to obtain a good assessment of the true Salmonella incidence status of these piglets. In addition, these piglets came from Salmonella-seropositive breeding herds [16] and had not been treated with antibiotics, as they were to be slaughtered. Thus, this approach could somewhat reflect what may be happening in nursery piglets from Salmonella-seropositive production herds.

The overall percentage of Salmonella-infected (MLN-positive) piglets was 36.5\% (95\% CI 31.9-41.4) but was variable across pig farms (from 17.5\% to 59.2\%). A similar proportion of piglets (37.3\%; 95\% CI 32.6-42.2) could be considered Salmonella shedders as the bacterium was found in their IC (Table 1). Few field studies have been carried out on Salmonella prevalence at this stage, and when performed through the sampling of live piglets, results suggested active infection but the recovery levels of fecal Salmonella were usually much lower $[7,17]$. Two major issues would help to understand the differences between this and previous studies. First, we analyzed $25 \mathrm{~g}$ of fecal content, the amount required according to the ISO 6579:2002/A1:2007 standard and significantly larger than that collected through swabbing. Second, this study only included piglets from breeding farms with high levels of Salmonella seropositivity. A good match was also found between animal infection and shedding at this age, with the odds of shedding Salmonella being more than 12 times higher for an MLN-positive piglet compared to an MLN-negative one (Table 3). This relationship was further supported by the detection of the same Salmonella serotype on MLN and IC in most $(82.7 \%)$ of the piglets that had been positive in both types of samples. Shedding the bacterium through feces is the main mechanism of transmission of Salmonella and is common when animals are infected for the first time or when infected animals suffer episodes of stress, such as commingling or transport [11]. Given the age of these piglets, they had probably been infected very recently, besides suffering such stress factors as they had been sent to slaughter. In addition, an unknown number of new infections may have also occurred during transport and/or lairage [18,19]. Altogether, this would help to explain the high level of shedding among these piglets. From these results, it can be derived that most of the post-weaning pigs that become infected with Salmonella are also asymptomatic, and in contrast to what was expected [2], it appears that when compared to older piglets, they would not be more clinically affected. Thus, salmonellosis may be easily overlooked during the nursery period as well, regardless of the use of antimicrobials. In any case, this high prevalence of infection and shedding was not a surprising result, since similar findings were observed in a previous study on weaned (4-wo) pigs from the same farms [16].

No differences were found regarding serological OD\% values between infected and non-infected piglets (median OD\% of 4.7 and 4.8, respectively), these values being similar to those found in piglets of the same age in other studies [20]. However, on average, OD\% values were much lower than those found in the previous study on 4-wo piglets from the same farms (15.9\%; [16]), evidencing the likely significant decay of maternally derived IgGs against Salmonella within the two weeks after weaning [7]. It seems that the beginning of the nursery may be a period of high susceptibility to the infection and that measures to prevent exposure to Salmonella should be encouraged at this time.

One of the aims of this study was to determine whether Salmonella infection from nursery units will be able to reach further production phases, that is, the growing units. For that purpose, floor fecal samples from the GDU, from each of corresponding breeding farms under study, were collected in order to detect Salmonella. All the gilt units were Salmonella positive, with an overall proportion of positive samples of $26.7 \%$ (Table 4 ). This figure would be within the expected range of Salmonella-positive fecal samples for growing/finishing pig units in Spain $[1,21]$ but probably underestimates the true proportion 
of positive samples, given the relative low sensitivity of the bacteriological culture when performed on fecal samples from asymptomatic animals [5].

The main serotypes detected in these gilt units were $S$. Rissen, followed by $S$. Derby and S. 4,[5],12:i:-. The three of them were also the most common serotypes detected in the piglets, suggesting that these serotypes were circulating between both production periods even when the GDU were located kilometers away from their corresponding nurseries (i.e., farm E). To further confirm this hypothesis, PFGE analysis was performed on Salmonella isolates when the same serotype was found in piglets and gilt units from a given farm. PFGE analysis showed that most of the Salmonella isolates from piglets were grouped with gilt isolates, indicating a high level of genetic similarity $(\geq 90 \%)$ between them. Despite the small number of isolates analyzed, this match was found at least once in all four farms where these isolates were recovered and it was detected for the three serotypes, supporting the maintenance of Salmonella infection between the nursery and the growing unit and the role that piglets may play in it.

Within a given nursery unit, the same clone of Salmonella could be detected for a long period of time ( $>150$ days apart) involving different batches of piglets. Besides, no particular temporal pattern of infection between piglets and gilt units was detected either (a given Salmonella isolate could be found at the same time or first in nursery piglets and later in the gilt units, or vice versa). These results suggested that cross-contamination between units within farms and/or a lack of proper pen hygiene are major issues in these farms, highlighting the difficulties of eliminating Salmonella from the farm environment despite high internal hygiene and biosecurity standards. These results would also help to explain, in part, the origin of the Salmonella infection in the GDU and the further Salmonella infection in sow herds [22].

It is worth noting that $S$. Derby appears as one of the most frequent serotypes found in breeding farms $(\sim 30 \%)$ [23] and is commonly found throughout the pig production pyramid, which would support the hypothesis that this serotype is easily transmitted by the transfer of animals between units or herds [24]. With regard to S. Rissen and S. 4,[5],12:i:-, both were also reported in the European survey mentioned above and both have experienced a worldwide expansion in the past few decades $[25,26]$. In a recent report from the Spanish Ministry of Agriculture, Fish and Food, the monophasic variants of $S$. Typhimurium and $S$. Rissen were the most prevalent serotypes found in a national survey carried out on slaughtered pigs in 2019 (35.4\% and 23.8\%, respectively), followed by $S$. Derby (13.1\%) [27]. Both S. Derby and S. 4,[5],12:i:- are among the main pig-related serotypes associated with human salmonellosis in the EU in the past few years [28-32], while $S$. Rissen is considered a significant cause of foodborne salmonellosis in Asia and southern European countries [26,33]. To the best of the authors' knowledge, there are no reports so far on the main Salmonella serotypes associated with contamination of piglet meat or showing possible links between consumption of piglet meat and human salmonellosis. However, considering these results, health authorities should be aware of the potential risk of contamination of piglet carcasses due to the arrival of infected piglets at the abattoir.

Ninety-eight percent of the Salmonella isolates displayed multidrug-resistant phenotypes, with most of them showing resistance profiles commonly reported in Salmonella (ACSSu, ACSSuT, ACST, etc.). No AMR was found against antibiotic classes considered of critical importance for humans, such as carbapenems and polymyxins [34], but a significant proportion of isolates $(12.9 \%)$ presented resistance to 3rd-generation cephalosporins and even to cefquinome (5.5\%), a 4th-generation cephalosporin. This type of resistance, detected only in $S$. Rissen isolates, was much more prevalent than that reported in pigs for the EU (1.1\%) [35]. The worldwide emergence of resistance to extended-spectrum cephalosporins in non-typhoidal Salmonella is already a matter of concern [36], particularly when harbored by Salmonella serotypes of potential zoonotic character [37]. In this case, most of the resistant isolates ( $75 \%$ ) were found in piglets intended for human consumption. Thus, they could be considered potential vectors for the transmission of this resistance to humans, although they never received antibiotics. 
In summary, nursery pigs can become subclinically infected and act as active carriers of Salmonella in a farm, as the same Salmonella clones were observed in piglets and in the GDU. This finding suggests that piglets play a significant role in the infection of finishing pigs in production farms as well. Therefore, Salmonella infection in nursery piglets should be considered a potential risk factor for abattoir contamination, and the control of Salmonella infection at this stage may help to decrease the risk of carcass contamination. Considering that a significant source of Salmonella for nursery pens would be the sows [16], sows would then be a significant source of Salmonella infection for gilts and finishing pigs $[38,39]$. Indeed, a recent risk assessment model adapted specifically for Spain showed that sow prevalence is a strong indicator of slaughter pig prevalence [40]. Our results support theirs. Defining proper strategies that prevent Salmonella shedding from sows should be a major goal in any production/breeding pig farm. Factors that could be related to Salmonella infection/shedding in sows (i.e., dry/pellet feed, inefficient disinfection protocols, type of floor, etc.) $[39,41,42]$ should then be avoided. The implementation of feed strategies (organic acids, essential oils, prebiotics, etc.) to reduce somehow the level of infection and shedding in the farms $[43,44]$, or even the vaccination of sows $[45,46]$, may also be advisable. These strategies could be implemented directly in nursery piglets as well $[47,48]$. In addition, minimizing the use of antibiotics in production/breeding farms would appear as another goal to prevent further spread of AMR to fattening pigs and gilts [26] and may reduce Salmonella shedding as well [49].

\section{Materials and Methods}

\subsection{Farm Selection}

The study was carried out on five multiplier/supplier swine breeding farms (herd size between 700 and 940 sows) from the northeast part of Spain (A, B, C, D, and E), where half of the Spanish pig census is concentrated. Farms A, B, and C belonged to one company and $\mathrm{D}$ and $\mathrm{E}$ to a different one. All these farms had shown Salmonella seroprevalence $\geq 50 \%$, and Salmonella was detected, on average, in $22 \%$ of the sow fecal samples analyzed from them [16]. The farms were chosen due to the farmers' and corresponding veterinarians' willingness to participate in the study. The sampling was carried out in two periods, between January 2012 and May 2013 (farms A, B, and C) and between February 2015 and February 2016 (farms D and E).

These breeding farms keep female weaned piglets as re-stocking gilts for other pig production farms. However, male weaned piglets are usually sent to slaughter for meat, either at weaning age ( $4 \mathrm{wo}$ ) or after a period of two weeks in the nursery (6 wo). The samples analyzed in this study belonged to 6-wo male piglets.

\subsection{Collection of Samples}

Piglet samplings were obtained at the abattoir. On a given day, whole intestinal packages from a certain number of animals from a given batch from a farm were collected directly at the slaughter line. There was no routine sampling schedule as the number of available piglets and sampling times were dependent upon both piglet availability from any of the five selected farms and abattoir readiness for collaboration that day. The intestinal packages were then submitted to the laboratory for immediate processing. The maximumpossible amount of mesenteric lymph nodes (MLN) and a minimum of $25 \mathrm{~g}$ of intestinal content (IC) were collected for bacteriological analysis. A piece of the diaphragm muscle was also collected for serological analysis.

During the period of piglet sampling, and every 3-4 months, floor fecal samples were also collected by farm veterinarians from GDU from the corresponding farms. In addition, serum samples from a representative number of these gilts were available for that period from the official eradication campaign against Aujeszky's disease. Fecal and serum samples were useful in identifying circulating Salmonella serotypes during the growing period and assessing the serological status of the growing gilts, respectively. 


\subsection{Bacteriology}

Detection of Salmonella isolates in both IC and MLN samples was performed according to the ISO 6579:2002/A1:2007 standard. Briefly, fresh MLN samples were first defatted, weighed, and externally decontaminated by dipping them into absolute alcohol and further flaming them. Afterward, the samples were homogenized in buffered peptone water (BPW; Panreac Química SAU, Castellar del Vallés, Spain) in 1:10 dilution and incubated for $18 \pm 2 \mathrm{~h}$ at $37 \pm 1{ }^{\circ} \mathrm{C}$. Thereafter, three drops (33 $\mu \mathrm{L}$ each) of incubated BPW were inoculated into a modified semisolid Rappaport Vassiliadis medium (MSRV; Oxoid Ltd., Hants, UK), and plates were incubated for $24 \pm 3 \mathrm{~h}$ at $41.5 \pm 1{ }^{\circ} \mathrm{C}$ (negative samples were re-incubated for an additional $24 \mathrm{~h}$ ). Ten microliters of the presumptive Salmonella growth (detected by the halo generated in MSRV after 24 or $48 \mathrm{~h}$ ) was transferred to two selective media (xylosine lysine deoxycholate (XLD) and brilliant green (BG) agars) (Panreac Quiímica SAU, Castellar del Vallés, Spain). One suspected colony per plate from each Salmonella-positive MLN and IC sample was confirmed biochemically (triple sugar iron (TSI) agar, urea agar, L-lysine decarboxylation medium, and indole reaction) (Panreac Química SAU, Castellar del Vallés, Spain) and further serotyped (sera obtained from the Statens Serum Institut, Copenhagen, Denmark) at the National Reference Laboratory for Animal Salmonellosis in Madrid, Spain, following the White-Kauffmann-Le Minor scheme [50].

\subsection{Pulsed-Field Gel Electrophoresis Analysis}

To assess the genetic relationship between the Salmonella strains shed by piglets and Salmonella contamination in the GDU, PFGE analysis was performed (CHEF-DR ${ }^{\circledR}$ III System, BIO-RAD, Madrid, Spain) on Salmonella isolates according to the pulse net protocol [51]. This technique is broadly recognized as a sensitive method for the molecular fingerprinting of Salmonella serotypes and is very useful for tracing the spread of this bacterium through the different pig production phases [24].

Only isolates from piglets' fecal samples and floor fecal samples from the gilt unit from the same farm that showed the same serotype were analyzed. If several isolates met this criterion, then a maximum of two piglet isolates and two gilt isolates per batch were analyzed.

PFGE pattern analysis was performed with the BIONUMERICS software (version 6; Applied Maths, Sint-Martens-Latem, Belgium) using Dice's coefficient and the unweighted pair group method with arithmetic averages (UPGMA dendrogram type) with a position tolerance of $1.5 \%$ and optimization of $2.0 \%$.

\subsection{Antimicrobial Agent Susceptibility}

AMR tests were also performed on isolates submitted for PFGE analysis in order to further characterize them. Susceptibility to aminopenicillins (A; ampicillin, amoxicillinclavulanic acid), phenicols (C; florfenicol), aminoglycosides (S; gentamicin, neomycin), sulphonamides and dihydrofolate reductase inhibitors ( $\mathrm{Su}$; trimethoprim-sulfamethoxazole), tetracyclins ( $\mathrm{T}$; tetracycline), cephalosporins (Cf; cephalexin, cefalotin, cefoperazone, ceftiofur, cefquinome), polymyxins (Po; colistin), carbapenems ( $\mathrm{Cm}$; imipenem), and quinolones ( $\mathrm{Na}$; flumequine, enrofloxacin, marbofloxacin) was assessed by the VITEK-2 automated system with VITEK GN96 cards (BioMérieux, Marcy-l'Étoile, France). The minimum inhibitory concentration (MIC) was obtained for each Salmonella strain and further classified as resistant, intermediate, or susceptible according to the Clinical and Laboratory Standard Institute recommendations [52]. An isolate displaying phenotypic resistance to at least three antimicrobial classes was considered multidrug resistant [53].

For assessing colistin resistance, MICs were determined by the broth microdilution method according to the ISO 20776-1:2006 standard. An epidemiological cutoff (ECOFF) value of $>2 \mathrm{mg} / \mathrm{L}$ was used for considering microbiological resistance according to the recommendations of the European Committee on Antimicrobial Susceptibility Testing [54]. 
Escherichia coli ATCC 25922 and E. coli B13129OT (kindly provided by Dr. González-Zorn's $\mathrm{lab}$ ) were used as quality negative and positive control strains.

\subsection{Serology}

For the detection of specific antibodies (IgG) against Salmonella spp., meat juice (MJ) from piglets' diaphragm muscle was used. MJ samples were obtained after freezing and further thawing a portion of the muscle. For gilts, blood serum samples were collected. Both piglet MJ and gilt serum samples were kept at $-20^{\circ} \mathrm{C}$ until their use. The Herdcheck Swine Salmonella ELISA test (IDEXX Laboratories, Westbrook, ME, USA) was used following the manufacturer's instructions. This test targets the main swine Salmonella serogroups (B, C1, and D). For piglets, results were presented as OD\% values. In the case of gilts, and given the expected low specificity of the ELISA test used [55,56], a cutoff value of $\mathrm{OD} \% \geq 40$ was deemed to classify a gilt as seropositive.

\subsection{Statistical Analysis}

Prevalence of Salmonella infection and shedding among piglets and their corresponding $95 \%$ confidence intervals $(95 \% \mathrm{CI})$ were estimated. Since the weight of MLN samples may differ among piglets and therefore may influence bacteriological results, the median MLN sample weight was compared between Salmonella-positive and Salmonella-negative piglets by means of the Mann-Whitney test for independent samples to detect potential bias. The relationship between piglet shedding and infection was assessed by mixed logistic regression after adjusting by season and considering farm as a grouping factor (gllamm module in STATA software). ELISA OD\% values between Salmonella-infected and non-infected piglets were compared using the Kruskal-Wallis test. The software STATA (STATA/IC 12.1. Stata-Corp. LP, College Station, TX, USA) was used for statistical analyses.

Author Contributions: Conceptualization, R.C.M.-J.; methodology, R.C.M.-J., M.B.-R., and A.C.-H.; formal analysis, R.C.M.-J., M.B.-R., and A.C.-S.; investigation, R.C.M.-J., M.B.-R., and A.C.-H.; writing-original draft preparation, M.B.-R. and R.C.M.-J.; writing-review and editing, M.B.-R., R.C.M.-J., C.M.M.-A., and A.C.-H.; supervision, R.C.M.-J.; and project administration and funding acquisition, R.C.M.-J. and C.M.M.-A. All authors have read and agreed to the published version of the manuscript.

Funding: This work was partially supported by the National Institute for Agricultural and Food Research and Technology (INIA; Ref. RTA2012-24) and by the Ministry of Science and Innovation (Ref. RTI2018-093915-B-I00). A.C.-H. was the recipient of a national fellowship (Ref. INIA-FPI 2014).

Institutional Review Board Statement: Not applicable. Ethical review and approval were waived for this study due to no interventions on live animals were performed. All animals sampled had been previously slaughtered at a commercial abattoir.

Informed Consent Statement: Not applicable.

Data Availability Statement: Data available upon request.

Acknowledgments: We thank pig production companies and their technical staff, farmers, and the abattoir for their collaboration in carrying out the field work.

Conflicts of Interest: The authors declare no conflict of interest.

\section{References}

1. European Food Safety Authority (EFSA). Report of the Task Force on Zoonoses Data Collection on the analysis of the baseline survey on the prevalence of Salmonella in slaughter pigs in the EU, 2006-2007. Part A: Salmonella prevalence estimates. EFSA J. 2008, 135, 1-111. [CrossRef]

2. Bonardi, S. Salmonella in the pork production chain and its impact on human health in the European Union. Epidemiol. Infect. 2017, 145, 1513-1526. [CrossRef] [PubMed]

3. Argüello, H.; Álvarez-Ordoñez, A.; Carvajal, A.; Rubio, P.; Prieto, M. Role of slaughtering in Salmonella spreading and control in pork production. J. Food Prot. 2013, 76, 899-911. [CrossRef] [PubMed] 
4. Swart, A.; Simons, R.; Evers, E.; Snary, E.; Swanenburg, M. Modeling of Salmonella contamination in the pig slaughterhouse. Risk Anal. 2016, 36, 498-515. [CrossRef]

5. Alban, L.; Baptista, F.M.; Møgelmose, V.; Sørensen, L.L.; Christensen, H.; Aabo, S.; Dahl, J. Salmonella surveillance and control for finisher pigs and pork in Denmark-A case study. Food Res. Int. 2012, 45, 656-665. [CrossRef]

6. Méroc, E.; Strubbe, M.; Vangroenweghe, F.; Czaplicki, G.; Vermeersch, K.; Hooyberghs, J.; Van Der Stede, Y. Evaluation of the Salmonella surveillance program in Belgian pig farms. Prev. Vet. Med. 2012, 105, 309-314. [CrossRef]

7. Nair, S.; Farzan, A.; Poljak, Z.; Friendship, R. Identifying Active Salmonella Infections in Swine Nurseries Using Serology and Bacterial Culture and Evaluating Associated Risk Factors. Animals (Basel) 2020, 10, 1517. [CrossRef]

8. Konstantinov, S.R.; Awati, A.A.; Williams, B.A.; Miller, B.G.; Jones, P.; Stokes, C.R.; Akkermans, A.D.; Smidt, H.; De Vos, W.M. Post-natal development of the porcine microbiota composition and activities. Environ. Microbiol. 2006, 8, 1191-1199. [CrossRef]

9. Gresse, R.; Chaucheyras-Durand, F.; Fleury, M.A.; Van De Wiele, T.; Forano, E.; Blanquet-Diot, S. Gut Microbiota Dysbiosis in Postweaning Piglets: Understanding the Keys to Health. Trends Microbiol. 2017, 25, 851-873. [CrossRef]

10. Bianchi, A.T.; Moonen-Leusen, H.W.; Van Der Heijden, P.J.; Bokhout, B.A. The use of a double antibody sandwich ELISA and monoclonal antibodies for the assessment of porcine IgM, IgG and IgA concentrations. Vet. Immunol. Immunopathol. 1995, 44, 309-317. [CrossRef]

11. Callaway, T.R.; Morrow, J.L.; Edrington, T.S.; Genovese, K.J.; Dowd, S.; Carroll, J.; Dailey, J.W.; Harvey, R.B.; Poole, T.L.; Anderson, R.C.; et al. Social stress increases fecal shedding of Salmonella Typhimurium by early weaned piglets. Curr. Issues Intest. Microbiol. 2006, 7, 65-71. [PubMed]

12. Weber, N.R.; Nielsen, J.P.; Hjulsager, C.K.; Jorsal, S.E.; Haugegaard, S.; Hansen, C.F.; Pedersen, K.S. Comparison of bacterial culture and qPCR testing of rectal and pen floor samples as diagnostic approaches to detect enterotoxic Escherichia coli in nursery pigs. Prev. Vet. Med. 2017, 143, 61-67. [CrossRef] [PubMed]

13. European Medicines Agency: EMA/CVMP/AWP/158821/2014-Concept Paper on Use of Aminoglycosides in Animals in the European Union: Development of Resistance and Impact on Human and Animal Health. July 2014. Available online: https: / www.ema.europa.eu/en/documents/scientific-guideline/concept-paper-use-aminoglycosides-animals-europeanunion-development-resistance-impact-human-animal_en.pdf (accessed on 30 November 2020).

14. European Medicines Agency: EMA/CVMP/CHMP/231573/2016-Updated Advice on the Use of Colistin Products in Animals within the European Union: Development of Resistance and Possible Impact on Human and Animal Health. July 2016. Available online: https://www.ema.europa.eu/en/documents/scientific-guideline/updated-advice-use-colistin-productsanimals-within-european-union-development-resistance-possible_en-0.pdf (accessed on 30 November 2020).

15. Quesada, A.; Porrero, M.C.; Téllez, S.; Palomo, G.; García, M.; Domínguez, L. Polymorphism of genes encoding PmrAB in colistin-resistant strains of Escherichia coli and Salmonella enterica isolated from poultry and swine. J. Antimicrob. Chemother. 2015, 70, 71-74. [CrossRef] [PubMed]

16. Casanova-Higes, A.; Marín-Alcalá, C.M.; Andrés-Barranco, S.; Cebollada-Solanas, A.; Alvarez, J.; Mainar-Jaime, R.C. Weaned piglets: Another factor to be considered for the control of Salmonella infection in breeding pig farms. Vet. Res. 2019, 50, 45. [CrossRef] [PubMed]

17. Ainslie-García, M.H.; Farzan, A.; Newman, J.E.; Friendship, R.M.; Lillie, B.N. Salmonella fecal shedding in pigs from birth to market and its association with the presence of Salmonella in palatine tonsils and submandibular lymph nodes at slaughter. Can. J. Vet. Res. 2018, 82, 249-255.

18. Mannion, C.; Fanning, J.; Mclernon, J.; Lendrum, L.; Gutierrez, M.; Duggan, S.; Egan, J. The role of transport, lairage and slaughter processes in the dissemination of Salmonella spp. in pigs in Ireland. Food Res. Int. 2012, 45, 871-879. [CrossRef]

19. Hernández, M.; Gómez-Laguna, J.; Luque, I.; Herrera-León, S.; Maldonado, A.; Reguillo, L.; Astorga, R.J. Salmonella prevalence and characterization in a free-range pig processing plant: Tracking in trucks, lairage, slaughter line and quartering. Int. J. Food Microbiol. 2013, 162, 48-54. [CrossRef]

20. Cevallos-Almeida, M.; Fablet, C.; Houdayer, C.; Dorenlor, V.; Eono, F.; Denis, M.; Kerouanton, A. Longitudinal study describing time to Salmonella spp. seroconversion in piglets on three farrow-to-finish farms. Vet. Rec. Open 2019, 6, e000287. [CrossRef]

21. García-Feliz, C.; Carvajal, A.; Collazos, J.A.; Rubio, P. Herd-level risk factors for faecal shedding of Salmonella enterica in Spanish fattening pigs. Prev. Vet. Med. 2009, 91, 130-136. [CrossRef]

22. Davies, P.R.; Funk, J.A.; Morgan-Morrow, W.E. Fecal shedding of Salmonella by gilts before and after introduction to a swine breeding farm. Swine Health Prod. 2000, 8, 25-29.

23. European Food Safety Authority (EFSA). Analysis of the baseline survey on the prevalence of Salmonella in holdings with breeding pigs, in the EU, 2008, Part A: Salmonella prevalence estimates. EFSA J. 2009, 7, 93. [CrossRef]

24. Denis, M.; Houard, E.; Fablet, A.; Rouxel, S.; Salvat, G. Distribution of serotypes and genotypes of Salmonella enterica species in French pig production. Vet. Rec. 2013, 173, 370. [CrossRef] [PubMed]

25. Gosling, R.J.; Mueller-Doblies, D.; Martelli, F.; Nunez-Garcia, J.; Kell, N.; Rabie, A.; Wales, A.D.; Davies, R.H. Observations on the distribution and persistence of monophasic Salmonella Typhimurium on infected pig and cattle farms. Vet. Microbiol. 2018, 227, 90-96. [CrossRef]

26. Campos, J.; Mourão, J.; Peixe, L.; Antunes, P. Non-typhoidal Salmonella in the Pig Production Chain: A Comprehensive Analysis of Its Impact on Human Health. Pathogens 2019, 8, 19. [CrossRef] [PubMed] 
27. Ministerio de Agricultura, Pesca y Alimentación (MAPA). Informe de Resultados 2019. "Programa de Vigilancia de Zoonosis y Resistencias a Antimicrobianos: Diseño del Programa, Toma de Muestras, Aislamiento, Identificación y Caracterización de Microorganismos Sometidos al Programa de Vigilancia, con Especial Referencia al Aislamiento e Identificación de Cepas de E. coli Productor de ESBL y/o AmpC y/o Carbapenemasas, 2019". 2020. Available online: https://www.mapa.gob.es/es/ganaderia/ temas/sanidad-animal-higiene-ganadera/2019_informevigilanciazoonosisyram5_tcm30-551462.pdf (accessed on 5 December 2020).

28. European Food Safety Authority (EFSA); European Centre for Disease Prevention and Control (ECDC). The European Union summary report on trends and sources of zoonoses, zoonotic agents and food-borne outbreaks in 2014. EFSA J. 2015, 13, 4329. [CrossRef]

29. European Food Safety Authority (EFSA); European Centre for Disease Prevention and Control (ECDC). The European Union summary report on trends and sources of zoonoses, zoonotic agents and food-borne outbreaks in 2015. EFSA J. 2016, 14, 4634. [CrossRef]

30. European Food Safety Authority (EFSA); European Centre for Disease Prevention and Control (ECDC). The European Union summary report on trends and sources of zoonoses, zoonotic agents and food-borne outbreaks in 2016. EFSA J. 2017, $15,5077$. [CrossRef]

31. European Food Safety Authority (EFSA); European Centre for Disease Prevention and Control (ECDC). The European Union summary report on trends and sources of zoonoses, zoonotic agents and food-borne outbreaks in 2017. EFSA J. 2018, 16, 5500. [CrossRef]

32. European Food Safety Authority (EFSA). Scientific report on the European Union One Health 2018 Zoonoses Report. EFSA J. 2019, 17, 5926. [CrossRef]

33. Pornsukarom, S.; Patchanee, P.; Erdman, M.; Cray, P.F.; Wittum, T.; Lee, J.; Gebreyes, W.A. Comparative Phenotypic and Genotypic Analyses of Salmonella Rissen that Originated from Food Animals in Thailand and United States. Zoonoses Public Health 2015, 62, 151-158. [CrossRef]

34. World Health Organization. Critically Important Antimicrobials for Human Medicine. 6th Revision. 2018. Available online: https:/ / apps.who.int/iris/bitstream/handle/10665/312266/9789241515528-eng.pdf?ua=1 (accessed on 30 November 2020).

35. European Food Safety Authority (EFSA); European Centre for Disease Prevention and Control (ECDC). The European Union Summary Report on Antimicrobial Resistance in zoonotic and indicator bacteria from humans, animals and food in $2017 / 2018$. EFSA J. 2020, 18, 6007. [CrossRef]

36. Seiffert, S.N.; Hilty, M.; Perreten, V.; Endimiani, A. Extended-spectrum cephalosporin-resistant Gram-negative organisms in livestock: An emerging problem for human health? Drug Resist. Updates 2013, 16, 22-45. [CrossRef] [PubMed]

37. Sevilla, E.; Vico, J.P.; Delgado-Blas, J.F.; González-Zorn, B.; Marín, C.M.; Uruén, C.; Martín-Burriel, I.; Bolea, R.; Mainar-Jaime, R.C Resistance to colistin and production of extended-spectrum $\beta$-lactamases and/or AmpC enzymes in Salmonella isolates collected from healthy pigs in Northwest Spain in two periods: 2008-2009 and 2018. Int. J. Food Microbiol. 2020, 10, 108967. [CrossRef] [PubMed]

38. Nollet, N.; Houf, K.; Dewulf, J.; Duchateau, L.; De Zutter, L.; De Kruif, A.; Maes, D. Distribution of Salmonella strains in farrow-to-finish pig herds: A longitudinal study. J. Food Prot. 2005, 68, 2012-2021. [CrossRef]

39. European Food Safety Authority (EFSA). Analysis of the baseline survey of Salmonella in holdings with breeding pigs, in the EU, 2008. Part B: Analysis of factors potentially associated with Salmonella pen positivity. EFSA J. 2011, 9, 2329. [CrossRef]

40. Animal and Plant Health Agency (APHA); Biomathematics and Risk Research Workgroup; Martínez, J.M.; McCarthy, C.; Taylor, R.A. Livestock Health and Food Chain Risk Assessment. EFSA J. 2020, 18, e181111. [CrossRef]

41. Funk, J.; Gebreyes, W.A. Risk factors associated with Salmonella prevalence on swine farms. J. Swine Health Prod. 2004, $12,246-251$.

42. Garrido, V.; Sánchez, S.; San Román, B.; Fraile, L.; Migura-García, L.; Grilló, M.J. Salmonella Infection in Mesenteric Lymph Nodes of Breeding Sows. Foodborne Pathog. Dis. 2020, 17, 411-417. [CrossRef]

43. Berge, A.C.; Wierup, M. Nutritional strategies to combat Salmonella in mono-gastric food animal production. Animal 2012, 6, 557-564. [CrossRef]

44. Tran, T.H.T.; Everaert, N.; Bindelle, J. Review on the effects of potential prebiotics on controlling intestinal enteropathogens Salmonella and Escherichia coli in pig production. J. Anim. Physiol. Anim. Nutr. 2018, 102, 17-32. [CrossRef]

45. De La Cruz, M.L.; Conrado, I.; Nault, A.; Perez, A.; Dominguez, L.; Alvarez, J. Vaccination as a control strategy against Salmonella infection in pigs: A systematic review and meta-analysis of the literature. Res. Vet. Sci. 2017, 114, 86-94. [CrossRef] [PubMed]

46. Smith, R.P.; Andres, V.; Martelli, F.; Gosling, B.; Marco-Jimenez, F.; Vaughan, K.; Tchorzewska, M.; Davies, R. Maternal vaccination as a Salmonella Typhimurium reduction strategy on pig farms. J. Appl. Microbiol. 2018, 124, 274-285. [CrossRef] [PubMed]

47. Omonijo, F.A.; Ni, L.; Gong, J.; Wang, Q.; Lahaye, L.; Yang, C. Essential oils as alternatives to antibiotics in swine production. Anim. Nutr. 2018, 4, 126-136. [CrossRef]

48. Fabà, L.; Litjens, R.; Allaart, J.; Van Den Hil, P.R. Feed additive blends fed to nursery pigs challenged with Salmonella. J. Anim. Sci. 2020, 98, skz382. [CrossRef] [PubMed]

49. Smith, R.P.; Andres, V.; Cheney, T.E.; Martelli, F.; Gosling, R.; Marier, E.; Rabie, A.; Gilson, D.; Davies, R.H. How do pig farms maintain low Salmonella prevalence: A case-control study. Epidemiol. Infect. 2018, 146, 1909-1915. [CrossRef]

50. Issenhuth-Jeanjean, S.; Roggentin, P.; Mikoleit, M.; Guibourdenche, M.; De Pinna, E.; Nair, S.; Fields, P.I.; Weill, F.X. Supplement 2008-2010 (no. 48) to the White-Kauffmann-Le Minor scheme. Res. Microbiol. 2014, 165, 526-530. [CrossRef] 
51. Ribot, E.M.; Fair, M.A.; Gautom, R.; Cameron, D.N.; Hunter, S.B.; Swaminathan, B.; Barrett, T.J. Standardization of pulsed-field gel electrophoresis protocols for the subtyping of Escherichia coli O157:H7, Salmonella, and Shigella for PulseNet. Foodborne Pathog. Dis. 2006, 3, 59-67. [CrossRef]

52. Clinical and Laboratory Standards Institute (CLSI). Performance Standards for Antimicrobial Susceptibility Testing, 29th ed.; Approved Standard, CLSI Document M100; Clinical and Laboratory Standards Institute: Wayne, PA, USA, 2019.

53. Magiorakos, A.P.; Srinivasan, A.; Carey, R.B.; Carmeli, Y.; Falagas, M.E.; Giske, C.G.; Harbarth, S.; Hindler, J.F.; Kahlmeter, G.; Olsson-Liljequist, B.; et al. Multidrug-resistant, extensively drug-resistant and pandrug-resistant bacteria: An international expert proposal for interim standard definitions for acquired resistance. Clin. Microbiol. Infect. 2012, 18, 268-281. [CrossRef]

54. European Committee on Antimicrobial Susceptibility Testing (EUCAST). Clinical Breakpoints and Dosing of Antibiotics. Version 10.0. Available online: https://www.eucast.org/clinical_breakpoints / (accessed on 30 November 2020).

55. Nollet, N.; Maes, D.; Duchateau, L.; Hautekiet, V.; Houf, K.; Van Hoof, J.; De Zuttera, L.; De Kruif, A.; Geers, R. Discrepancies between the isolation of Salmonella from mesenteric lymph nodes and the results of serological screening in slaughter pigs. Vet. Res. 2005, 36, 545-555. [CrossRef]

56. Vico, J.P.; Engel, B.; Buist, W.G.; Mainar-Jaime, R.C. Evaluation of three commercial enzyme-linked immunosorbent assays for the detection of antibodies against Salmonella spp. in meat juice from finishing pigs in Spain. Zoonoses Public Health 2010, 57, 107-114. [CrossRef] 